\title{
Aerial vehicle surveys of other planetary atmospheres and surfaces: imaging, remote-sensing, and autonomy technology requirements
}

\author{
Larry A. Young $^{*}$, Gregory Pisanich ${ }^{\mathrm{b}}$, Corey Ippolito ${ }^{\mathrm{b}}$, Rick Alena $^{\mathrm{c}}$ \\ ${ }^{a}$ Army/NASA Rotorcraft Division, MS 243-12, ${ }^{b}$ QSS Group, Inc. Computational Sciences Division, \\ MS 269-3, ' Computational Sciences Division, MS 269-4, NASA Ames Research Center, Moffett \\ Field, CA USA 94035-1000
}

\begin{abstract}
The objective of this paper is to review the anticipated imaging and remote-sensing technology requirements for aerial vehicle survey missions to other planetary bodies in our Solar system that can support in-atmosphere flight. In the not too distant future such planetary aerial vehicle (a.k.a. aerial explorers) exploration missions will become feasible. Imaging and remote-sensing observations will be a key objective for these missions. Accordingly, it is imperative that optimal solutions in terms of imaging acquisition and real-time autonomous analysis of image data sets be developed for such vehicles.
\end{abstract}

Keywords: aerial imaging, surveys, planetary aerial vehicles, aerial explorers, UAV, simulation.

\section{INTRODUCTION}

Many planetary missions involving the use of aerial vehicles have been proposed ${ }^{8}$. A considerable body of research has focused on the aircraft design challenges of these vehicles. However, only cursory treatment has been given to the imaging and remote-sensing ramifications of such missions. This work sets out to address this situation by searching out the common threads with respect to imaging and remote-sensing of a wide range of notional aerial explorer missions. In that respect, two broad categories of aerial explorer imaging/remote-sensing missions immediately suggest themselves: missions in which the surface of a planetary body is observed and terrain features of interest are identified and those missions where the atmospheric flow field and chemical constituents are to be assayed. The first category includes aerial survey missions to Mars, Titan, and Venus (where there is both adequate atmospheric density for flight and a discrete and accessible planetary surface). The later category includes aerial flow field or chemistry measurements made in the upper atmospheres of the outer planet gas giants (where there are no discrete or accessible surfaces to the planetary cores).

In the context of these two general aerial survey mission categories, recommendations are made as to requirements and capabilities for imaging cameras, data storage and transmittal systems, remote-sensing systems such as lidar, radar, thermal emission spectrometry and other techniques. In particular, the operational and environmental constraints of such systems are discussed with respect to a number of notional aerial explorer missions. The necessity for the integration of science instrument suites with aerial vehicle navigation and mission planning systems are also discussed. An integrated approach is necessary because of the need to perform real-time three-dimensional mapping of terrain or atmospheric flow fields for scientific investigations as well as aerial vehicle navigation and hazard avoidance.

Uninhabited Aerial Vehicles (UAVs) have been, or are envisioned to support many different tasks on Earth. These include military (reconnaissance, or search and destroy), local (monitoring crops, power lines, or borders) and long range civil monitoring (ice flows, weather patterns). The mission of a planetary air vehicle may be to search for subtle signs of life (as in water or methane on Mars) or characterizing weather patterns and water vapor updrafts on Jupiter and other gas giant planets.

\footnotetext{
* larry.a.young@ nasa.gov; phone 1650 604-4022; fax 1650 604-6717
} 
Although terrestrial and planetary vehicles and missions may seem similar, planetary vehicles will need to be smarter, more efficient, and robust than their earthbound brethren. To achieve their goals, these planetary aerial vehicles may need to work as part of a large system of systems (orbiters, mother and daughter ships, rovers). They may also be part of a mission that is distributed in time. Examples of such a distributed time approach to missions include: successive flights of similar vehicles or the distribution of sensors that provide data back to the aerial vehicle during the flight, but also persist beyond the flight to return data to the mission scientists for months afterward.

Planetary vehicles will be required to navigate and perform their tasks in uncertain and largely unknown environments. In general, they will not have the luxury of the positive position, speed, and altitude sensing afforded by GPS. For planets such as Mars, better terrain and sensor data is beginning to become available (via orbiters such as NASA's Mars Odyssey and the ESA's Mars Express), but at the resolution needed by aerial vehicles, this information will only get them close to the area of interest. In the case of the exploration of the atmosphere of gas giants, very little positioning information will be available, but little may be needed, as these vehicles will be navigating within and around general weather, wind, and wind-borne aerosol patterns. For this reason, both categories of vehicles will likely navigate using search and find strategies that are unlike those used for terrestrial searches. Rather than exhaustive searches over known areas, these vehicles will use broad stochastic or biologically based behavioral searches to find evidence of areas of interest, followed by highly efficient searches in those areas that follow the data to a conclusion or resolution of a specific line of scientific inquiry.

Planetary aerial vehicles will need to operate with limited resources. Because they will not be able to land, return, or refuel before completing their mission (fixed-wing versions of aerial explorers, that is), these vehicles will have limited time on station to perform their work. Because of the need for lightweight construction, they will carry limited fuel/energy, electrical power, and sensor resources. Most research will need to be performed within one flight, or multiple flights of successive single flight vehicles.

Because of the distance from Earth and the significant communication turn-around time, these vehicles will necessarily need to fly and make decisions autonomously. There will be no human in the loop; at best there may be encouragement or recommendations from Earth that may be minutes or hours old. Exploration vehicles will need to be able to make decisions based on their best guess of the data that they have at the time, trading off resources and time in the decisionmaking. In addition to sensing and recognizing information, these vehicles will also need to be able to recognize something that is unfamiliar - primarily by finding things that do not match the "typical" characteristics for that environment. Therefore, the paper concludes with a discussion of the general class of information technology problem suggested by robotic navigation - investigation - in uncertain or unknown environments (which, with the arguable exception of Mars, all aerial explorer missions to other planetary bodies fall into).

\section{CATEGORIZATION OF POTENTIAL AERIAL EXPLORER MISSIONS}

Aerial exploration missions can be divided in two broad categories: those that entail surface imaging and interaction of various forms, and those that perform atmospheric environmental sensing. Aerial explorers for planetary bodies such as Earth, Mars, Titan (Saturn's largest moon), and Venus - because of their discrete and accessible surfaces beneath their atmospheres - can perform both mission categories (though perhaps in separate individual missions). Aerial explorers for outer gas-giant planets such as Jupiter, Saturn, Neptune, and Uranus - because their solid inner cores are inaccessible because of incredible pressures and temperatures - can only perform atmospheric environmental sensing missions in the higher-altitude, outer atmospheres of these planets. Nonetheless, an extensive array of mission scenarios, goals, and vehicle configurations can be envisioned that fit within these two mission categories for various planetary bodies of interest.

There are three general types of mission capabilities that can be provided by planetary aerial vehicles: observation of the surface, subsurface, or atmosphere; surface interaction; and utility. The first type benefits from the close-range measurements that the aerial explorer can make while traversing over large distances; geophysical measurements (magnetic field and ground penetrating radar) benefit especially. Surface interactions call for the aerial explorer to be able to land and take off from unprepared sites and/or air-deploy sensors and robotic devices. The utility category 
includes tasks such as acting as a telecom relay for other ground or air assets for over-the-horizon communication, i.e. supporting and enabling science investigations. In some cases, the planetary aerial vehicles will act in total isolation, until completion of the mission and subsequent relay of data to Earth. In other cases the aerial explorers will work in concert with a network of robotic devices, intelligent sensor packages, and autonomous robots (e.g. landers, rovers, and orbiters).

This paper touches briefly on the aerial survey requirements and constraints of two illustrative examples of these mission categories: aerial explorers for studying the Martian surface and the outer atmosphere of Jupiter.

\subsection{Surface imaging and interaction}

The majority of our work involving aerial explorers has focused on surface imaging and surface interaction for Mars exploration ${ }^{2,3,5.7,8}$. Both fixed-wing and vertical takeoff and landing (VTOL) vehicles have been studied. Surface interaction, therefore, in our investigations has taken on two forms: air-deployment of intelligent sensors and small robotic devices from fixed-wing aerial explorers, and the landing and return from remote sites of interest with vertical lift aerial vehicles. This work primarily discusses surface imaging and surface interaction in the context of fixed-wing aerial explorers. The chief challenges for performing the search for past or present water, precursor-to-life organic compounds, and life itself on Mars (and perhaps Titan) are: 1. robust flight control, especially while flying at low-attitude and near the ground, 2. autonomously finding terrain features of interest to investigate in a uncertain or unknown environment, and 3. devising means to build in mission persistence to maximize scientific return on investment, mostly by means of effecting informational or physical "symbiosis" with multiple robotic assets, i.e. a kind of robotic ecosystem ${ }^{3,4}$. Further, the study of the inner rocky planets provides important clues as to geologic processes that have important implications for our planet.

\subsection{Atmospheric environment sensing}

The whole issue of planetary climatology and meteorology is an area of current discussion and interest ${ }^{27}$. In many regards, studying the atmospheric processes of other planets - so as to better understand our own planet - raises even more profound questions than does the search for water and life beyond Earth in our Solar system and others. For such a study (including a large diverse collection of planets) provides important clues as to the evolution of our atmosphere/biosphere and the long-term survivability of our species and others. Fixed-wing aerial explorers quite rightly dominate this general category of missions. There is little need for VTOL-capability if the primary objective of the planetary mission is the study of the planetary body's atmospheric dynamics and chemical constituents. We have performed only limited studies to date in this aerial explorer mission category ${ }^{11}$. The chief challenges for performing such studies using aerial vehicles are: 1. achieving robust flight control, especially in hurricane-force zonal winds and extreme turbulence and density gradients well beyond terrestrial experienced magnitudes, 2 . prolonging flight duration and extending vehicle range through a variety of means -- including thermal and dynamic soaring and partial reliance on semi-buoyant lift for flight in the outer planets' atmospheres - to acquire as a minimum regional-scale, diurnal (or other large time-scale) atmospheric measurements, and 3. acquiring and relaying data to orbiters and other in-flight aerial vehicles to insure data transfer back to Earth over large time-scales (i.e. greater than a couple of hours).

\section{A "MAGNIFICENT DESOLATION..." "}

The alien landscapes of other planetary bodies are quite unlike anything on Earth. True, there are analog sites on Earth where certain geological and astrobiological features seem to echo features seen on other planets, but in many regards these similarities are only artifices of convenience. The surfaces of planetary bodies such as Mars, Venus, and Titan

\footnotetext{
${ }^{\S}$ Quoted from Buzz Aldrin, Apollo 11, with reference to observing the lunar surface prior to setting foot on the surface, as the second man in history to do so.
} 
indeed reflect "magnificent desolation." If, as currently prioritized, the primary research thrust of NASA planetary science missions is to address the question of past and current life on other planetary bodies, then the whole question of aerial surveys must be assessed in that context. Therefore, the question becomes: how can the existence or nonexistence of water-formed/modified minerals, trace organic compounds, or micro-fossils in rocks be realistically evaluated from the air, using an autonomous Mars airplane flying at Mach 0.4-0.5 at one kilometer above the Martian surface ${ }^{8}$ ? Signs of ancient water and perhaps life will be extremely subtle to divine. Not only will high levels of vehicle autonomy need to be provided for such a search but new approaches relying upon stochastic and, perhaps, bio-inspired search and find flight behaviors will need to be devised for such aerial surveys. That is also why, in addition to performing aerial imaging and remote sensing, it is also vitally important to acquire "ground-truth" during the aerial explorer surveys ${ }^{6,7}$. A variety of mechanisms have been proposed and studied in prototype form in order to capture such ground-truth ${ }^{3,8}$.

To arrive at such new search and find strategies and ground-truth acquisition methodologies it is first necessary to define the terrain features of interest that might be sought after. Table 1 contains a brief list of these. This in turn will suggest approaches by which aerial explorers might look for those terrain features of interest - inevitably yielding heuristics, rules, and hypotheses that will be incorporated in the autonomous system implementation of a planetary aerial vehicle. Further, definition of such a set of terrain features of interest will also enable the definition of requirements for the sensors to be used for the aerial vehicle surveys.

Table 1. - Terrain Features of Interest, Their Evaluation, and Implications

\begin{tabular}{|c|c|c|c|}
\hline $\begin{array}{l}\text { Science } \\
\text { Goal }\end{array}$ & $\begin{array}{l}\text { Terrain } \\
\text { Feature } \\
\text { Interest }\end{array}$ & How to Evaluate & Possible Sensors and Imaging/Survey Strategies \\
\hline \multirow[t]{10}{*}{$\begin{array}{l}\text { Search for } \\
\text { Water }\end{array}$} & Gullies & $\begin{array}{l}\text { Erosion on hillsides } \\
\text { possibly created by water. }\end{array}$ & $\begin{array}{l}\text { Sensitive (scanning laser) altimeter to map terrain. } \\
\text { Imaging comparison against known classifier forms } \\
\text { at Mars analog facilities. }\end{array}$ \\
\hline & \multirow[t]{5}{*}{$\begin{array}{l}\text { Ancient River } \\
\text { Basins }\end{array}$} & Linear ground depressions. & $\begin{array}{l}\text { Sensitive (radar) altimeter, mapping of terrain to find } \\
\text { and follow possible river channel from start to finish. } \\
\text { Image, characterize and identify terrain color } \\
\text { changes associated with water-modified mineral } \\
\text { deposits. }\end{array}$ \\
\hline & & \multirow[t]{2}{*}{$\begin{array}{l}\text { Chemical distributions } \\
\text { along river bank. }\end{array}$} & $\begin{array}{l}\begin{array}{l}\text { Onboard spectrometer to identify and map } \\
\text { distributions. }\end{array} \\
\end{array}$ \\
\hline & & & $\begin{array}{l}\text { Delivery of chemical-assay contact pods (single or } \\
\text { long linear rope-type) to verify actual composition. }\end{array}$ \\
\hline & & \multirow{2}{*}{$\begin{array}{l}\text { Rock distributions from } \\
\text { large boulders to smaller } \\
\text { rocks that would have been } \\
\text { deposited by ancient water } \\
\text { flow. }\end{array}$} & $\begin{array}{l}\text { Integration of spectrometer, altimeter, and imaging } \\
\text { sensor data to map and recognize size and } \\
\text { distribution of rocks. }\end{array}$ \\
\hline & & & $\begin{array}{l}\text { Vision-based assessment of terrain rockiness and } \\
\text { distribution. Accurate delivery of small mobile robot } \\
\text { that can image and sample rocks and boulders up } \\
\text { close. }\end{array}$ \\
\hline & \multirow[t]{2}{*}{$\begin{array}{l}\text { Water Hillside } \\
\text { Outflows }\end{array}$} & \multirow[t]{2}{*}{$\begin{array}{l}\text { Depressions or caves in } \\
\text { hillsides where water may } \\
\text { have flowed out of and may } \\
\text { still exist }\end{array}$} & $\begin{array}{l}\text { Accurate navigation using prior 3D imaging of the } \\
\text { hillsides and rivers leading to them. Sensitive } \\
\text { forward-looking radar to image hillside to identify } \\
\text { depressions. Forward-looking spectrometer to } \\
\text { identify possible residual water. }\end{array}$ \\
\hline & & & $\begin{array}{l}\text { Accurate placement of tetherbot with close up } \\
\text { spectrometer and imaging capabilities. Persistent } \\
\text { tetherbot supports analysis across multiple seasons at } \\
\text { this site. }\end{array}$ \\
\hline & \multirow[t]{2}{*}{$\begin{array}{l}\text { Identification } \\
\text { of water ice in } \\
\text { glacial form. }\end{array}$} & \multirow[t]{2}{*}{$\begin{array}{l}\text { Identification of water- } \\
\text { based glacier and terrain } \\
\text { beneath }\end{array}$} & $\begin{array}{l}\text { Downward-looking radar or Lidar to identify } \\
\text { differences between upper surface and ground } \\
\text { below. Spectrometer to identify water in ice and } \\
\text { possible outflows. }\end{array}$ \\
\hline & & & $\begin{array}{l}\text { Contact drop pod that can return surface and near } \\
\text { surface content to verify glacier. }\end{array}$ \\
\hline
\end{tabular}




\begin{tabular}{|c|c|c|c|}
\hline & & & $\begin{array}{l}\text { Deployment of subsurface penetrator pod to image } \\
\text { and sense glacial material. Deployment of multiple } \\
\text { persistent penetrators may provide verification of } \\
\text { glacial drift. }\end{array}$ \\
\hline & \multirow[t]{2}{*}{$\begin{array}{l}\text { Existence of } \\
\text { Subsurface } \\
\text { water. }\end{array}$} & \multirow[t]{2}{*}{$\begin{array}{l}\text { Water located below the } \\
\text { surface. }\end{array}$} & $\begin{array}{l}\text { 3D mapping of surface to identify low areas. } \\
\text { Penetrating radar or spectrometer to identify } \\
\text { subsurface areas. }\end{array}$ \\
\hline & & & $\begin{array}{l}\text { Deployment of surface pods to characterize surface, } \\
\text { deploy subsurface penetrator to gather imaging and } \\
\text { chemical signatures. }\end{array}$ \\
\hline \multirow[t]{4}{*}{$\begin{array}{l}\text { Search for } \\
\text { Life }\end{array}$} & $\begin{array}{l}\text { Existence in } \\
\text { Ancient Lake } \\
\text { Bottoms } \\
\text { (Striated rocks) }\end{array}$ & $\begin{array}{l}\text { Striated rocks on hillsides } \\
\text { may indicate riverbeds and } \\
\text { fossil areas. }\end{array}$ & $\begin{array}{l}\text { 3D mapping of terrain. Imaging identification of } \\
\text { rock areas. }\end{array}$ \\
\hline & \multirow[t]{3}{*}{ Subsurface life } & \multirow{3}{*}{ 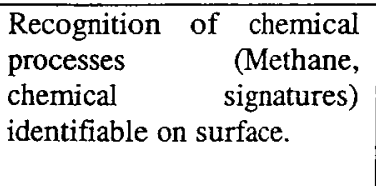 } & $\begin{array}{l}\text { Large scale search of surface for spectral signatures. } \\
\text { Lower altitude mapping of promising area. }\end{array}$ \\
\hline & & & Deployment of surface imaging and contact pods. \\
\hline & & & $\begin{array}{l}\text { Deployment of subsurface penetrators to image and } \\
\text { subsurface life. }\end{array}$ \\
\hline
\end{tabular}

\section{THE LANDSCAPE OF SKY: MAPPING THE WIND...}

Understanding the atmospheric dynamics and chemistry of the upper troposphere of outer gas giant planets in our solar system could be greatly expedited by planetary missions incorporating the use of robotic gliders. Such outer planet gliders could have in-atmosphere flight endurance an order of magnitude greater than that achieved by atmospheric probes. Such longevity would allow a glider to function as a radio relay link for a short-lived atmospheric probe targeted to $100 \mathrm{Bar}$ depths as recommended by the National Academy of Science ${ }^{28}$. Returning data to an over-flying orbiter is a major problem because of the RF-attenuating character of the Outer Planet atmospheres and the long communicating distances involved. There are many technical challenges inherent in the development of such vehicles, not the least of which is achieving low risk in-atmosphere gliding or soaring flight in hurricane force winds. The development of such aerial explorer aeronautical and information technologies would have applications to terrestrial environmental sensing problems as well.

Aerial vehicle concepts for the exploration of outer planet, gas giants have been previously examined ${ }^{11,12}$. Because of the higher gravity field of gas giant planets, and consequently the potential energy just waiting to be tapped, gliders are an almost obvious design solution for flight in the atmosphere of gas giant planets. Atmospheric probes, such as the Galileo probe, will only have a life span (once released into the atmosphere) of only one to two hours at best, because ultimately the probes descend to regions of such great pressure and temperature conditions that their failure through crushing or heat death is inevitable. Such atmospheric probes promise only a hit and miss approach to critical measurements. A robotic glider would have significantly greater longevity than probes,- even when only accounting for conservative, achievable L/D's (lift to drag ratios) and minimum sink rates. Further, if the outer planet gliders were imbued with the capability of performing autonomous dynamic and thermal soaring in the gas giant atmospheres, then long endurance flight duration (limited only by vehicle battery power) is potentially achievable. (Incorporation of deployable wind-turbine devices and/or kinetic rechargers - mass-spring systems for drawing energy from atmospheric turbulence excitation - will also need to be evaluated as to their ability to extend vehicle battery life.) Further, the ability to execute even limited maneuverability would allow for the active interrogation and measurement of atmospheric dynamics of these planets (by means of Lidar and thermal imaging, techniques which will likely also be required to achieve autonomous soaring).

The Galileo atmospheric probe measured winds ranging from $\sim 200$ miles per hour at the one bar reference altitude to 450 miles per hour at the 20 bar altitude. Outer planet gliders will have only limited, but essential, control as they are swept along by the winds much higher than even severe storm wind velocities seen on Earth. (Information regarding the Jovian atmosphere and other outer planets can be found in several references ${ }^{13-17}$, for example.) Currently, progress is being made to employ small robotic aircraft to monitor terrestrial hurricanes and severe storms ${ }^{18-20}$. Additionally, other 
researchers are considering from an information technology perspective the ability to perform dynamic and thermal soaring of gliders ${ }^{21}$. Further, for low-altitude flight (higher atmospheric pressure/density levels), the trade-offs between lift generated by lifting-surfaces and buoyancy can also be examined. In this regards, the lower-altitude outer planet gliders might take on "flight" attributes similar to underwater autonomous gliders ${ }^{22,23}$. Such past technology efforts will aid in the overall effort. The extreme range of temperatures and pressures resulting from glider flight in the outer troposphere of the outer planet gas giant atmospheres dictates the development and/or validation of new materials and aircraft construction techniques. One such approach is the use of inflatable wings and aircraft structures ${ }^{24}$.

Several questions exist as to whether or not such outer planet glider versions of aerial explorers are viable. First, is it possible to arrive at compact (stowed for transport), structurally robust glider configurations with high lift over drag ratios and therefore low minimum sink rates compatible with flight in the atmosphere of the outer gas giant planets? Second, is it possible to define/develop adaptive flight control laws and software to allow autonomous thermal and dynamic soaring? Third, can these glider designs and autonomous software be demonstrated through simulation to allow sustained flight in hurricane force (or greater in the case of gas giant planets) winds and turbulence?

Different vehicle configurations will likely be required for different bands of altitude within which the gliders fly, and to which purpose they are employed (Fig. 1a-b). For example, higher altitude gliders for the 1-10 Bar pressure reference altitudes will look very similar to terrestrial gliders. In addition to weather pattern measurements, such higher altitude gliders could also serve as telecom relays for probes that descend to deeper depths. Gliders flying deeper into an outer planet atmosphere, as the low-altitude flyer seen in Fig. 1b, would have lower aspect ratios, more compact planforms, and perhaps derive part of their lift from buoyancy effects in addition to wing aerodynamic lift. All outer planet glider concepts would be subject to unique design challenges such as stowing and transporting them in aeroshell entry vehicles, then deploying or releasing upon descent through the planetary atmosphere.
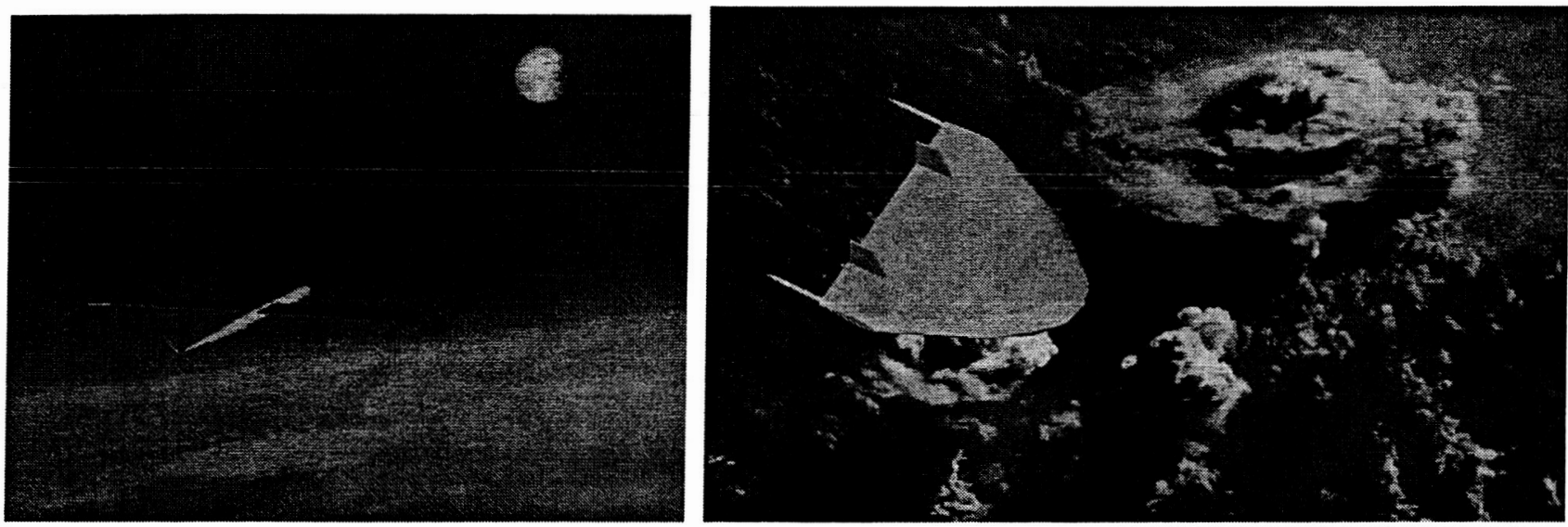

Fig. 1. Notional Jovian gliders: (a) "conventional" glider with inflatable wings and folding tail boom and (b) lower-altitude flyer.

A Mars aerial explorer mission that might take on greater emphasis in the future is one where atmospheric samples are taken in-flight ${ }^{26}$. Recent spectroscopic measurements (from the ESA Mars Express orbiter and from ground-based telescopes) suggest that there may be unexpectedly high levels of methane in the upper atmosphere of Mars. Whether the source is biological or non-biological is subject to speculation. An aerial explorer outfitted with an air-sampling device and spectroscopic instruments could be employed to pinpoint the sources (at the surface or sub-surface) of the methane. The search and find behaviors of such a methane "sniffing" aerial explorer would be very reminiscent of the attributes of classic computer science optimal search algorithms (wherein only discrete scale measurements can be made at a given point in time and space). These air-sampling search behaviors would include identifying and following scalar gradients of methane levels, periodically performing various perturbations (zig-zagging, spiral patterns, and circling flight) in flight path to make sure that global and not local minima are being pursued, and as needed, random commanded waypoints to escape regions of negligible levels, or neutral gradients, of atmospheric methane. 


\section{AERIAL EXPLORER IMAGING/REMOTE-SENSING TECHNOLOGY NEEDS}

\subsection{Intelligent low power lightweight sensors}

Aerial explorers will require an integrated suite of multiple sensors, to include vision, spectrometers, lidar, radar, and atmospheric-chemistry sensors. These sensors will necessarily have dual roles, sharing use as navigation and control and as science sensors. Such a sensor will also need to be intelligent, having both the ability to process and interpret the datasets on board to a higher information level, and also to self adapt, or tune itself to increase the ability to find data in the area in which it finds itself. Table 2 is a notional "wish list" of such sensors as applied to general categories of aerial explorer missions. Only the "science instruments" are noted; sensors for navigation, flight control, and safety of flight health monitoring are not listed. Severe power and weight constraints will have to be met (requiring significant technology investments to address them) in order to enable this broad suite of sensors to be carried by the aerial explorers of the future. There is a clear opportunity by the imaging and remote sensing community to effect the successful realization of such vehicles and missions by laying the early technological and developmental groundwork to enable these sensors. This is, in part, the primary purpose of this paper. Aerial explorers will only be as good as the sensors they carry.

Table 2. - Wish List of Smart Sensors and their Notional Attributes.

\begin{tabular}{|c|c|}
\hline Sensors & Attributes \\
\hline \multicolumn{2}{|l|}{ Ground Sensing and Navigation } \\
\hline Camera & $\begin{array}{l}\text { Can image downward, forward, and off axis. } \\
\text { Can Zoom. } \\
\text { Can automatically track specified item of interest. } \\
\text { Can autonomously create and return a mosaic of a given area. }\end{array}$ \\
\hline Spectrometer & $\begin{array}{l}\text { Can image downward, forward, and off axis. } \\
\text { Can successfully image at wide field (to show general existence) and } \\
\text { narrow field.(to recognize location) } \\
\text { Can automatically track specified item of interest. } \\
\text { Can autonomously create and return a 2D mosaic of a given area. } \\
\text { Can create overlay maps of different spectral images in parallel. }\end{array}$ \\
\hline Laser and/or Radar altimeter & $\begin{array}{l}\text { Can image downward, forward, and off axis. } \\
\text { Sensitive to sub meter accuracy. } \\
\text { Can autonomously create and return a 3D map or mesh of a given area. }\end{array}$ \\
\hline Infrared Sensor & $\begin{array}{l}\text { Can image downward, forward and off axis. } \\
\text { Could be used to image hydrothermal vents. } \\
\text { Could be used to image glacier areas covered by dust and dirt. }\end{array}$ \\
\hline Ground Penetrating Radar & $\begin{array}{l}\text { Can image downward, forward, and off axis. } \\
\text { Can autonomously create and return a 3D map of area. } \\
\text { Can return surface information up to } 5 \text { meters below the ground. }\end{array}$ \\
\hline Magnetometer & $\begin{array}{l}\text { Could provide } 2 \mathrm{D} \text { and } 3 \mathrm{D} \text { models of magnetic variance. } \\
\text { Could be used to direct aircraft toward the existence of mineral } \\
\text { deposits. }\end{array}$ \\
\hline Drop Probe & $\begin{array}{l}\text { Ability to perform close up and micro imaging of material on ground. } \\
\text { Contact sensors capable of recognizing different chemical compounds. } \\
\text { Ability to provide data back to aerial vehicle. } \\
\text { Persistent beyond vehicle flight. }\end{array}$ \\
\hline Tetherbot Probe & $\begin{array}{l}\text { Probe deployable on hillside allowing movement of sensors up and } \\
\text { down the hill. } \\
\text { Includes cameras that can recognize rock types and micro image rocks. } \\
\text { Ability to provide data back to the vehicle. } \\
\text { Persistent beyond vehicle flight. }\end{array}$ \\
\hline Ground Penetrator probe & $\begin{array}{l}\text { Can penetrate } 1-5 \text { meters below surface when dropped from } 100 \\
\text { meters. } \\
\text { Contains visual sensors } \\
\text { Contains contact sensors to perform chemical processes. }\end{array}$ \\
\hline
\end{tabular}




\begin{tabular}{|l|l|}
\hline Atmospheric Environment Sensing \\
\hline LIDAR & $\begin{array}{l}\text { Can image downward, forward and off axis. } \\
\text { Provides ranging from reflective surfaces. } \\
\text { Could provide backscatter data, allowing 2D and 3D models of terrain. }\end{array}$ \\
\hline Doppler Radar & $\begin{array}{l}\text { Can provide advanced warning of turbulence, and high winds to allow } \\
\text { advanced flight planning and maneuvering. } \\
\text { Can provide 3d maps of weather and atmospheric phenomena. }\end{array}$ \\
\hline Chemical Spectroscopy (methane, other chemicals) & $\begin{array}{l}\text { Would provide information to control the aircraft toward altitudes or } \\
\text { locations where specific chemicals exist. } \\
\text { Would provide 2D and 3D models of atmospheric chemicals. } \\
\text { Could provide 2D and 3D models that could be used to predict } \\
\text { emissions emanating from ground sources. }\end{array}$ \\
\hline
\end{tabular}

Figures 2 and 3 show graphics from initial simulation work performed by our team to examine not only mission design and autonomous system technologies for aerial explorers, but to begin to investigate questions regarding the sensor suite for such explorers. Figure $2 \mathrm{a}-\mathrm{b}$ shows the vantage viewpoint of two different camera mountings (forward- and sideward pointing) for a Mars fixed-wing aerial explorer. The explorer model in the simulation is a generic vehicle configuration and is not related to any existing concept.
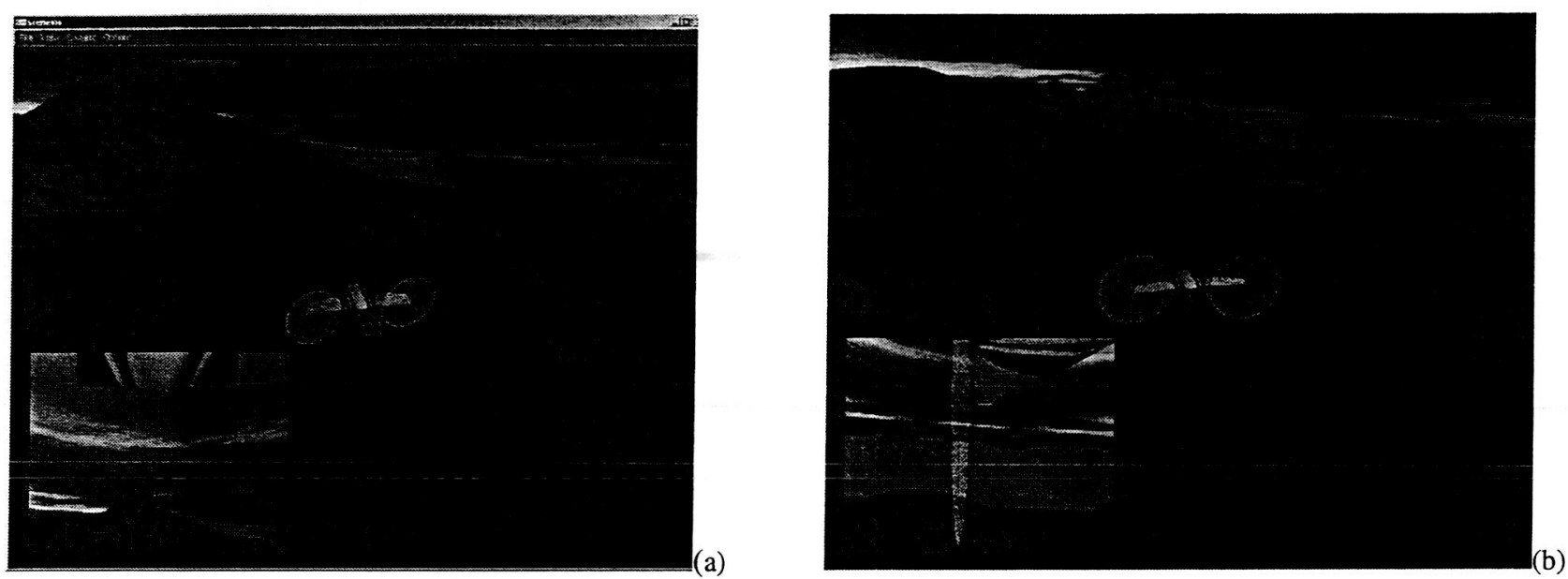

Figure 2. (a) forward- and (b) sideward-pointing camera positions

Figure 3 shows simulation work directed towards infrared sensors for such an aerial explorer. Such a sensor reflects, in part, an interest in searching for hypothetical surface hydrothermal vents on the Martian surface (refer to the reddishorange blotches in the simulation screenshot and window inset).

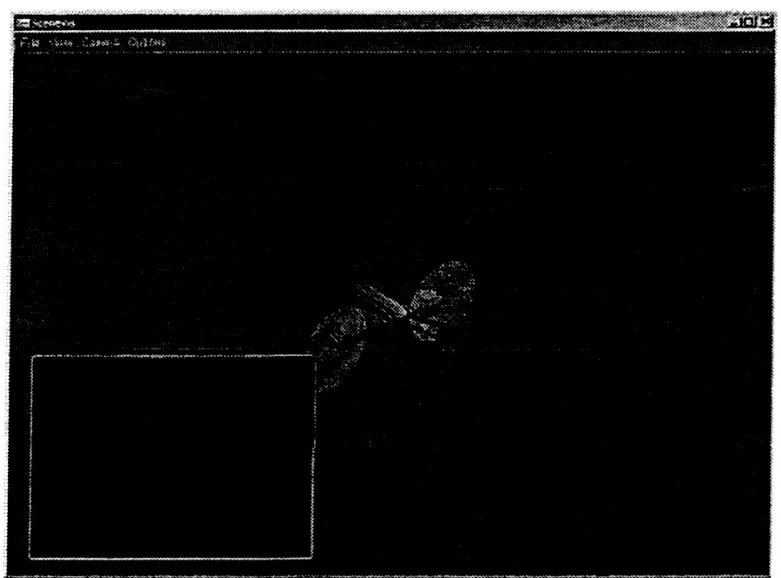

Figure 3. Pan and tilt infrared camera sensor in simulation 


\subsection{Search and find strategies \& autonomy}

Planetary aerial vehicle concepts and mission scenarios embody technical challenges beyond their terrestrial counterparts, the increasingly ubiquitous UAV. Unlike terrestrial UAVs that can be provided with scalable autonomy (i.e. varying levels of human operator monitoring and intervention), because of the significant light-time delays, planetary aerial explorers must be fully autonomous with high levels of mission and contingency planning capability.

A key challenge for aerial explorer missions is to how to maximize scientific return. A typical aerial mission (perhaps covering hundreds or thousands of kilometers) might have a duration measured in hours as compared to months for surface rovers and years for orbiters. Such aerial vehicles may need to survive a landing and continue to transmit recorded data and/or to act as a fixed surface station. Additionally, the aerial explorers could air-deploy and distribute near surface features of interest a network of intelligent sensors and small robotic devices. In both cases this would be the ultimate manifestation of entry, descent, and landing system (EDLS) technology. Given this ability to survive landing, the aerial explorer then becomes an element in a system of sensors and robotic devices, key components that are air-deployed. In effect, the mission architecture comprises a small but potent robotic ecosystem of heterogeneous robotic systems, both internal and external autonomous agents.

All planetary flight vehicles will share a common technology requirement: the need for unprecedented vehicle autonomy to perform unique science missions while flying in relatively unknown environments. Top-level goals are:

1. Reliable mission capability without any human intervention and with high-levels of mission/contingency planning in an unknown/uncertain environment;

2. Reliable/robust solutions for precision navigation (non-GPS) and flight control;

3. Robust and effective robotic system of systems integration.

Autonomous system technology derived from this proposed program will become the "gold standard" for uninhabited aerial vehicles, whether terrestrial or planetary. As such, there should readily be significant adoption of concepts and technologies from this initiative into many applications.

An important ancillary aspect of our work is examining how bio-inspiration can yield innovative mission concepts and how bio-inspired autonomy has advantages over other intelligent systems approaches ${ }^{2-8}$. In the two general mission categories identified earlier, bio-inspiration leads to the examination of the behavioral patterns of creatures of the air and those of the sea. Missions entailing surface imaging and interaction can perhaps best draw inspiration from the behaviors of creatures of the air. Those missions entailing atmospheric environment sensing might be best served by examining the behaviors of creatures of the sea (that often rely on three-dimensional locomotion. In both cases, though, survival of these creatures is highly dependent upon keen vision or, alternatively, other highly attuned senses.

Table 3. - Representative Parametric Considerations in Developing and Evaluating (in Simulation) Aerial Explorer Autonomy

Environment: Atmospheric Models, Terrain Models (Actual, Modeled, Generated, Generated with Actual or Modeled Insets), Winds, Weather, Atmospheric Flows.

Aerial Platforms: Configuration, Carrying Capacity, Dynamics, Flexibility, How Deployed

Resources: Power, Fuel, Flight Time, Communication Rates

Onboard Sensors: Control and interface with, number, type, placement, capacity, dual use (navigation and science), sensor models, communication rates, processor power, "intelligence."

Deployable Sensors: Number and mix of sensors carried by vehicle, sensor type, sensor capabilities (contact, video), communications capability, length of use (persistence)

Autonomous Capabilities: Data analysis capabilities, autonomy level ${ }^{8}$, resource management, integrated health management, processing speed, processing Supplemented by space-borne assets.

System Architecture: Single Aircraft, Multiple Aircraft (Sequential or Parallel Flights), Multiple Aircraft with Different or Complementary Capabilities, Flights with Ground and/or Space Based Assets.

Mission Methods and Goals: Single Mission, Series of Missions, Missions with Persistence.

Resiliency to Failures and Contingencies: Power Failures (Engine, Batteries), Communications, Internal and External

Pods, Failure of one or more aircraft. 
Table 3 is a short representative list of the parametric considerations that need to be addressed in order to arrive at robust aerial vehicle autonomy in an uncertain or unknown environment. This is the minimum condition for the successful realization of aerial explorers. A high degree of confidence must be established (via simulation as well as limited field/flight demonstrations) that a specific mission and vehicle design combination will yield scientific success, well before a launch opportunity would become available.

\subsection{Simulation and mission design for intelligent aerial survey}

Planetary aerial vehicle missions will present unprecedented challenges as compared to past planetary missions. As noted earlier, in many "ways, planetary aerial vehicle development will represent the "gold standard" for UAV autonomous. system technology. Table 4 summarizes a notional "wish list" of autonomous science analysis, flight control, and decision-making software and simulation capabilities to effectively enable the development of future planetary aerial vehicles. Inherent in this software and simulation wish list is the theme of bio-inspiration as applied to mission scenarios, autonomous flight behaviors, and robotic symbiosis and ecosystems.

Table 4. - Wish List of Onboard Autonomous Data Analysis and Decision-Making Software Capabilities

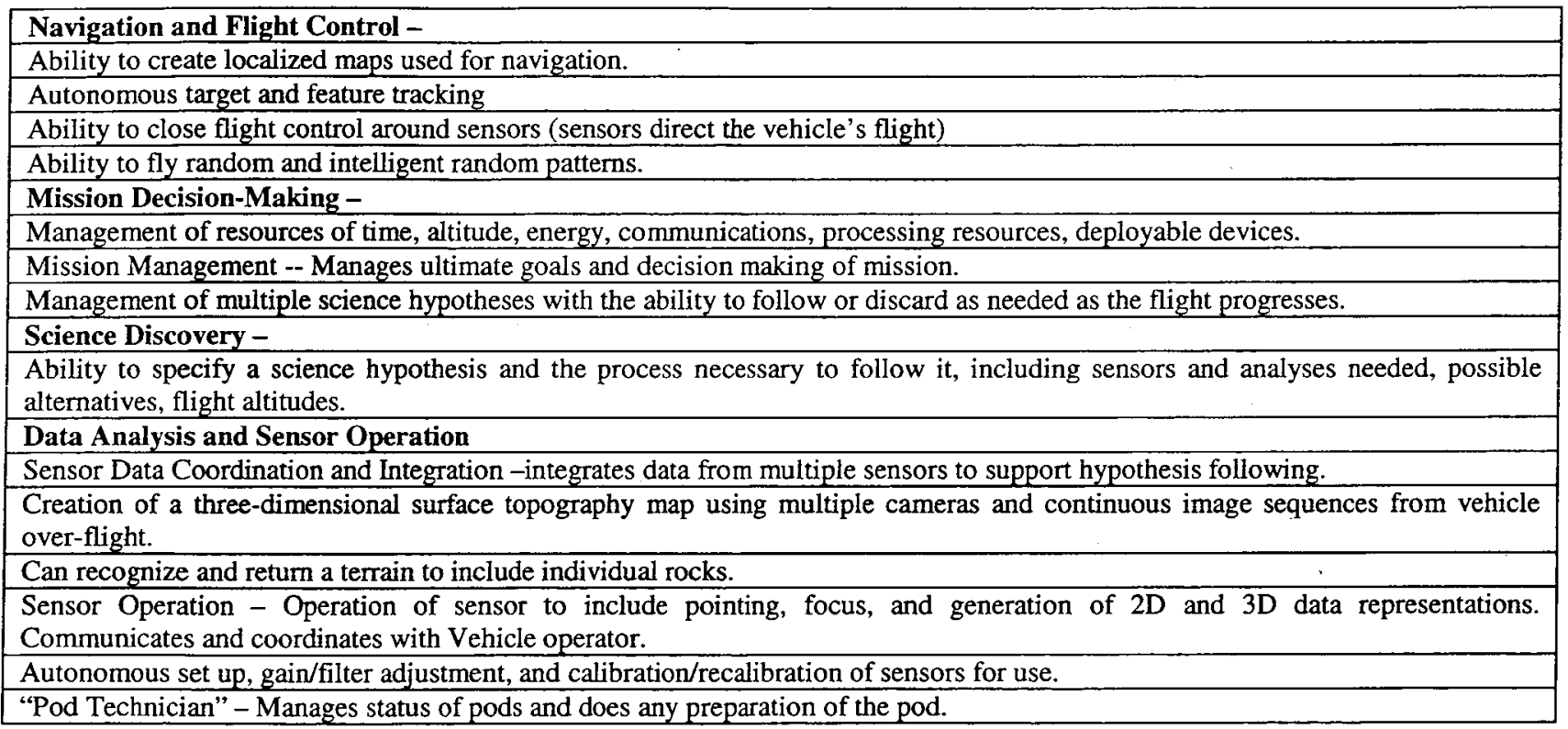

Ideally a combination of simulation and flight test demonstrations of aerial vehicle technologies could be accomplished prior to mission design finalization and launch. As there will be considerable difficulty in finding analog environments for vehicle terrestrial flight demonstrations, much of the mission/vehicle design and evaluation will have to be borne by simulation analysis. (For example, an aerial vehicle would have to fly at an altitude of over $100 \mathrm{kft}$ on Earth to match the mean atmospheric density at Mars' surface. Accomplishing such flight demonstrations are very costly and difficult to perform.) Nonetheless it is important to acknowledge the limitations of simulation for such purposes: models might not match actual characteristics of the vehicle, the environment, the overall mission constraints; simulation models can only be tested to some inevitable fidelity level less than actual; models need to be validated as much as possible (even if there is a non-optimal match between the planetary and terrestrial analog environments and the mission and demonstration scenarios).

To support our research, we have developed the Reflection architecture and simulator ${ }^{7}$ which allows real and fast time simulations of vehicles, sensors, and software in terrestrial and planetary environments. Using an open, flexible architecture, Reflection allows simulation components and software to be easily integrated as necessary to meet a 
mission design. The atmosphere, flight models, terrain, and target distributions are all variable. In addition, the Reflection architecture allows simulation to be executed on the target hardware in the lab as well as on the vehicle while in flight. Simulations can be evaluated first in the 3D visual environment and then run offline hundreds of times in the same or different simulation conditions. Figure 4 shows a typicai screen shot during a simulation run. This system was used for the development of the autopilot study described later in this paper.

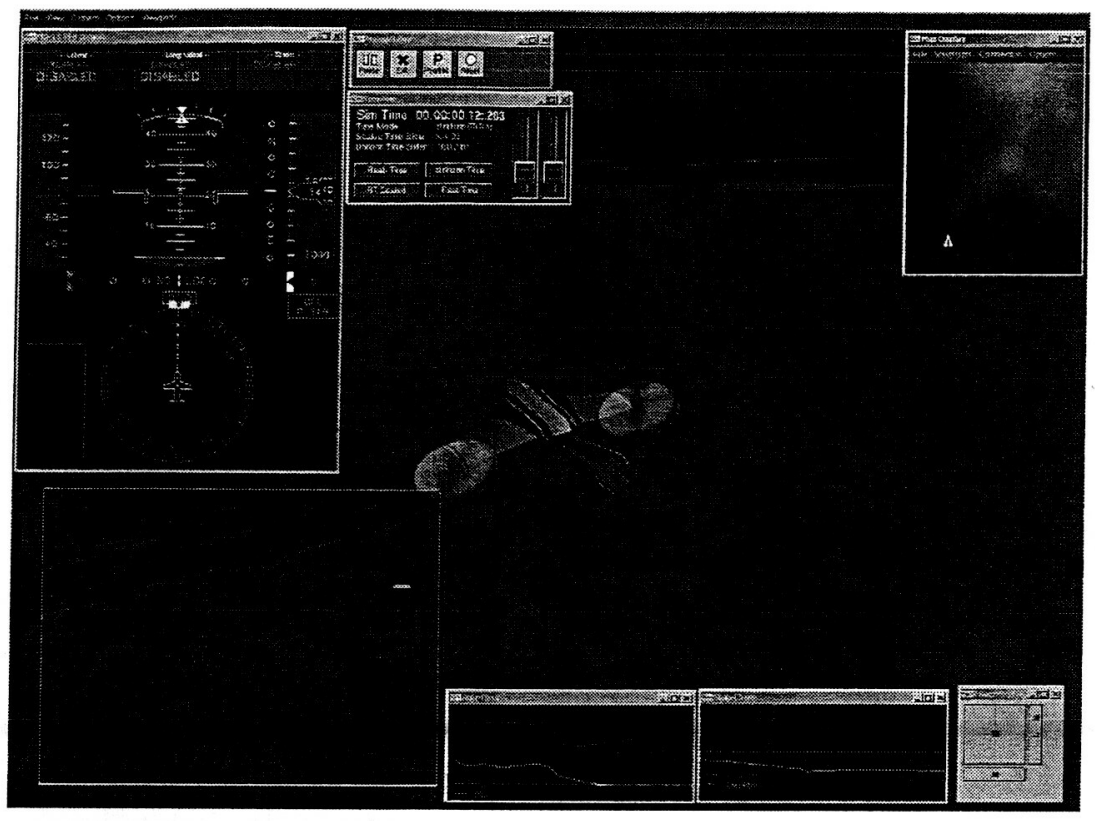

Figure 4. Reflection Simulator Interface showing vehicle, terrain, and autonomous software monitoring displays.

\subsection{Getting the data back home}

As seen for their ground-based relatives (i.e., robotic rovers), voluminous data sets will likely be the norm for aerial vehicle planetary science missions. However, unlike rover missions, there will be no scientist existing in the mission execution loop. Like their ground based relatives, planetary aerial vehicles will need to be able to access and sample the environment so that they can confirm or deny hypotheses as they go along. They will need to deploy pods that can reach the ground and return data, or surrogate air vehicles that can fly to lower or higher altitudes to sample areas that would be physically impossible.

Even if the planetary aerial vehicle meets all its design and mission objectives, there are still considerable remaining challenges to address. First and foremost is the challenge of getting the acquired imaging data back to Earth. Because of the data demands, and the likely available communication resources, the vehicles and probes must intelligently filter the data that they gather and maintain. Rather than necessarily gigabytes of data, the information that they would return back to earth might largely consist of the tested hypotheses and the data that supported or invalidated them. Because the vehicle may not be able to fly and communicate at the same time, the vehicle will need to be highly robust, capable of surviving a crash landing and then processing and returning the data that has been gathered.

\section{INITIAL SIMULATION RESULTS FOR MISSION \& IMAGING SYSTEM DESIGN}

Simulation has become an invaluable tool for designing and evaluating imaging systems for NASA Mars robotic rovers ${ }^{29}$. In a similar manner, the work noted in this paper takes initial steps towards developing simulation tools for imaging surveys for planetary aerial vehicles. Given the likely high costs of developing missions for such planetary aerial vehicles, it is essential to arrive at robust, flexible aerial imaging systems. The following simulation experiment shows the utility of using simulation to test and develop control systems for aerial exploration. 


\section{1}

\section{Closing the Loop around Sensors}

Our hypothesis in designing the control systems used in these experiments was that the explorer would perform substantially better when sensor information was taken into account, and a system that could balance between several different strategies would outperform a system that would use a single search behavior, regardless of apparent success.
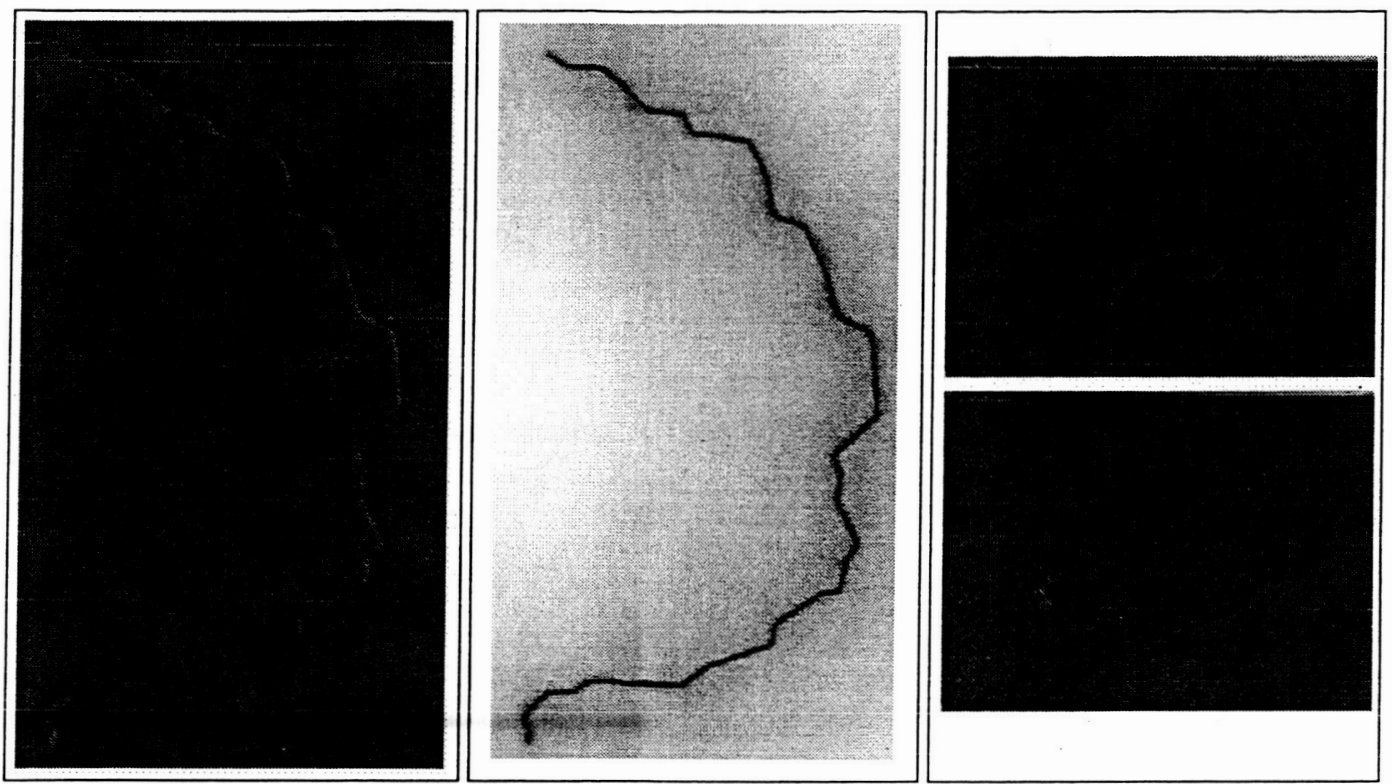

Figure 5. Views of simulated terrain: Overhead (Left), river plain (center), image showing depth of river (top right), $3 / 4$ view showing extent of river.

The environment used in our simulation consisted of a large featureless terrain with the exception of a large gully that runs randomly through it, as shown in Figure 5. The entire search area is 180,000 square miles, with 75 targets distributed randomly in the environment based on three distribution strategies: (i) $1 / 3$ of the targets are randomly distributed over the entire search area; (ii) $1 / 3$ of the targets were randomly distributed but concentrated near the gully based on a Gaussian distribution; and iii) 1/3 of the targets are distributed based on a random blend between (i) and (ii).

We simulated an aerial explorer cruising at Mach 0.7 in the Martian atmosphere at an altitude of $5000 \mathrm{ft}$, with a total search time of 1 hour (which is optimistic given estimates in the literature). We also developed five behavioral search strategies whose success is dependent on the distribution of targets in the environment, as detailed in table 5.

Table 5. Flight exploration behaviors and success heuristics.

\begin{tabular}{|l|l|}
\hline Behavior & Heuristic \\
\hline Grid Search & Targets concentrated in an area (directionally) \\
\hline Spiral Search & Targets concentrated in an area (non-directionally) \\
\hline Terrain Following & Targets are concentrated in the dried riverbed \\
\hline Random Walk & Targets are uniformly distributed over entire area \\
\hline Emotional CEL Network & Combines random-walk and terrain-following, with neither being favored. \\
\hline
\end{tabular}

The experiment simulates a downward facing camera that captures an image when the aircraft is $3.7 \mathrm{~km}$ from the location where the previous snapshot was taken, as the aerial explorer traverses the terrain. The camera has an aspect ratio of 1:1, with a field of view angle of 60 degrees, capturing images as large $4 \mathrm{~km}$ per side depending on the terrain height. In addition to returning images, the camera area was used to identify whether the targets of interest were visible to the aircraft at any time. Figure 6 shows examples of the five behaviors and the image records they produced. Figure 7 shows close ups of the image coverage of three of the behaviors. 


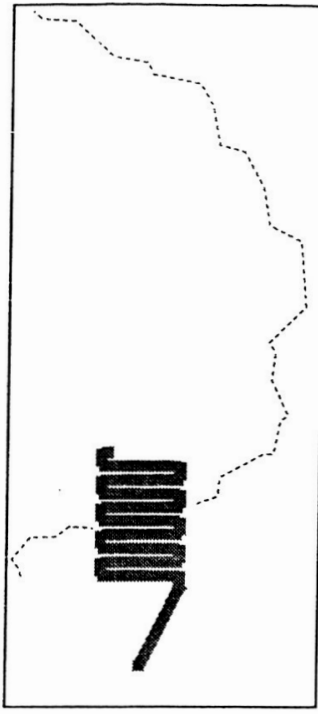

(a)

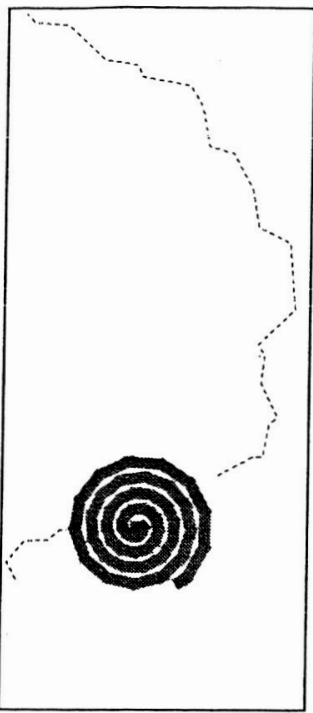

(b)

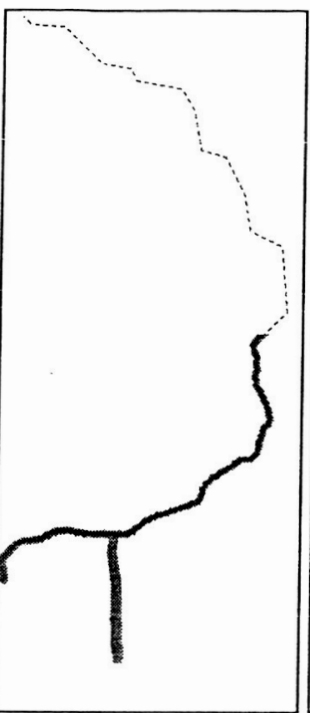

(c)

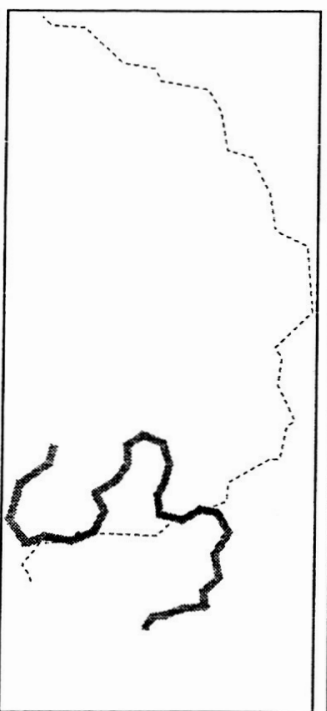

(d)

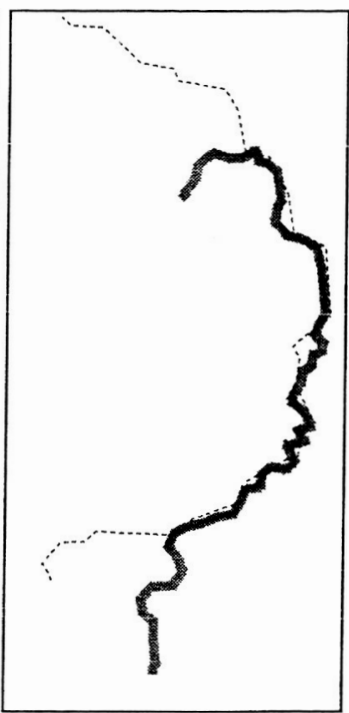

(e)

Figure 6. Graphical Imaging of Search Area using Experimental Search Behaviors (a) Grid Search (b) Spiral Search (c) Terrain Following (d) Random Walk (e) CEL System
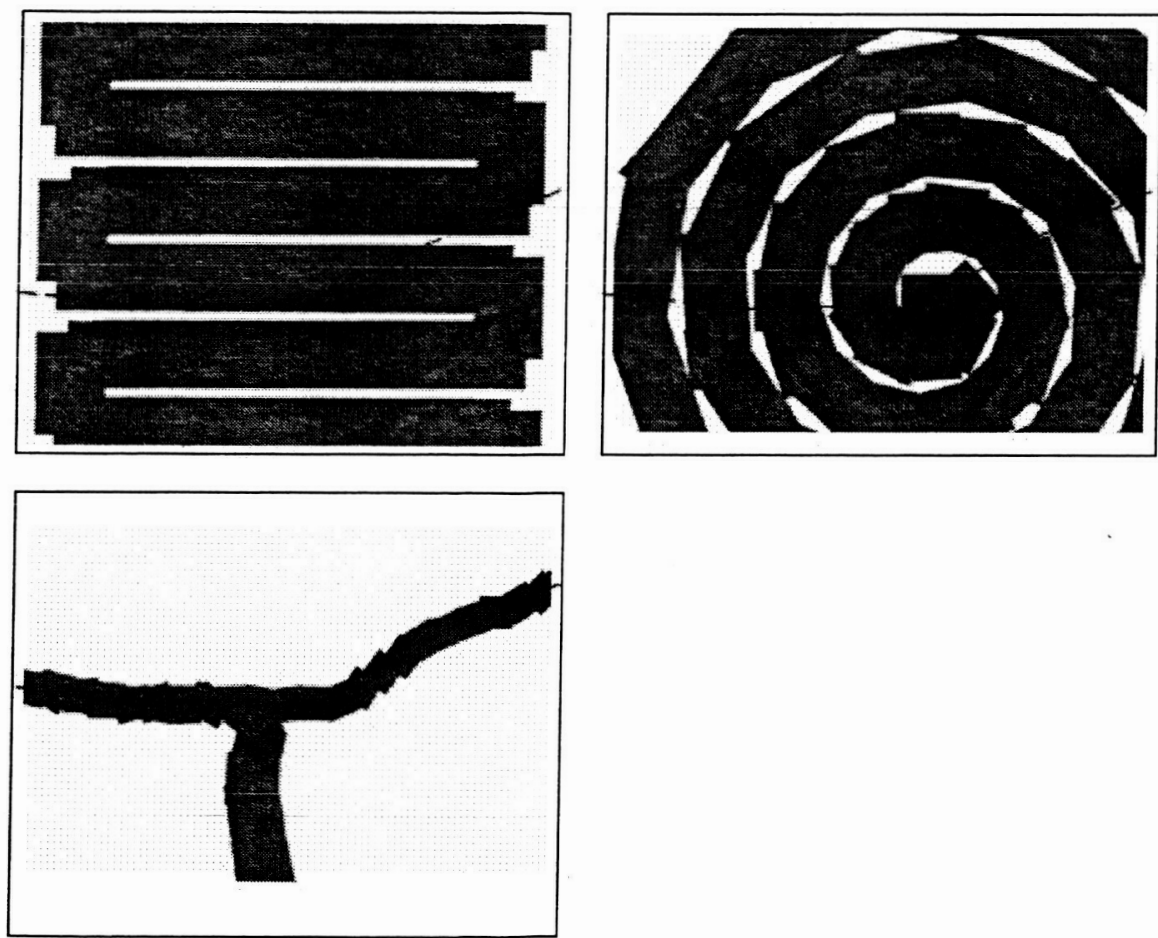

Figure 7. Close up detail of simulated aerial vehicle imaging: Grid (upper left), Spiral, Slope following (bottom left).

We used the behaviors to close the loop between sensor information and flight controls in order to maximize the goal of identifying targets. The grid and circling behavior searches in Figure 6 (a) and (b) and 7 represent a traditional waypoint commanded control system with decoupled sensor and downward facing camera. The results of the experiments performed with these autopilots showed that they did no better than a random walk of the area (Figure 6 (d)) as shown in Figure 8. 


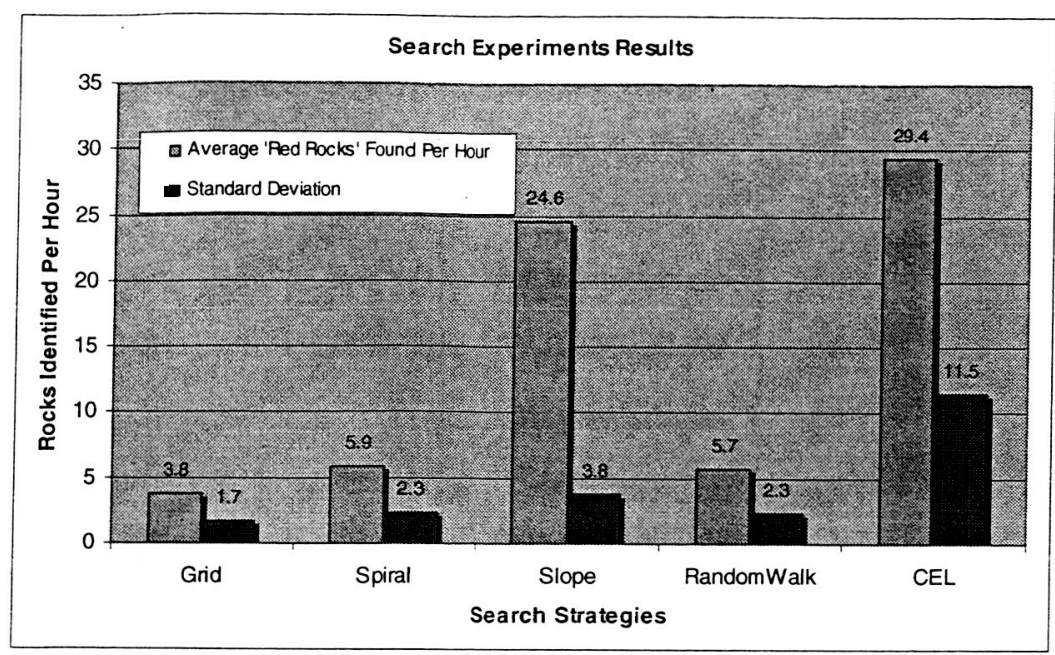

Figure 8. Experimental results showing rocks identified per hour using 5 different control search strategies

A terrain following autopilot was then designed that closed the loop on an auxiliary sensor, (laser altimeter), since terrain altitude is an indirect indicator of the target distribution. The autopilot performed substantially better than the original autopilots as shown in Figure 8, which supported the first part of our hypothesis on closing the loop on sensor information. However, the autopilot would often miss opportunities to image targets that were slight outliers, as shown on the left image of Figure 9. The amount of uncertainty in the distribution (deviation in the normal distribution about the riverbed) has a large effect on the success of the slope following autopilot, and when targets are randomly generated without regard to terrain height, the slope following performs no better than the random walk. This kind of uncertainty is expected to be an aspect of planetary exploration; if there is certainty about the environment and existence of target objects, there would be no need to perform the search.
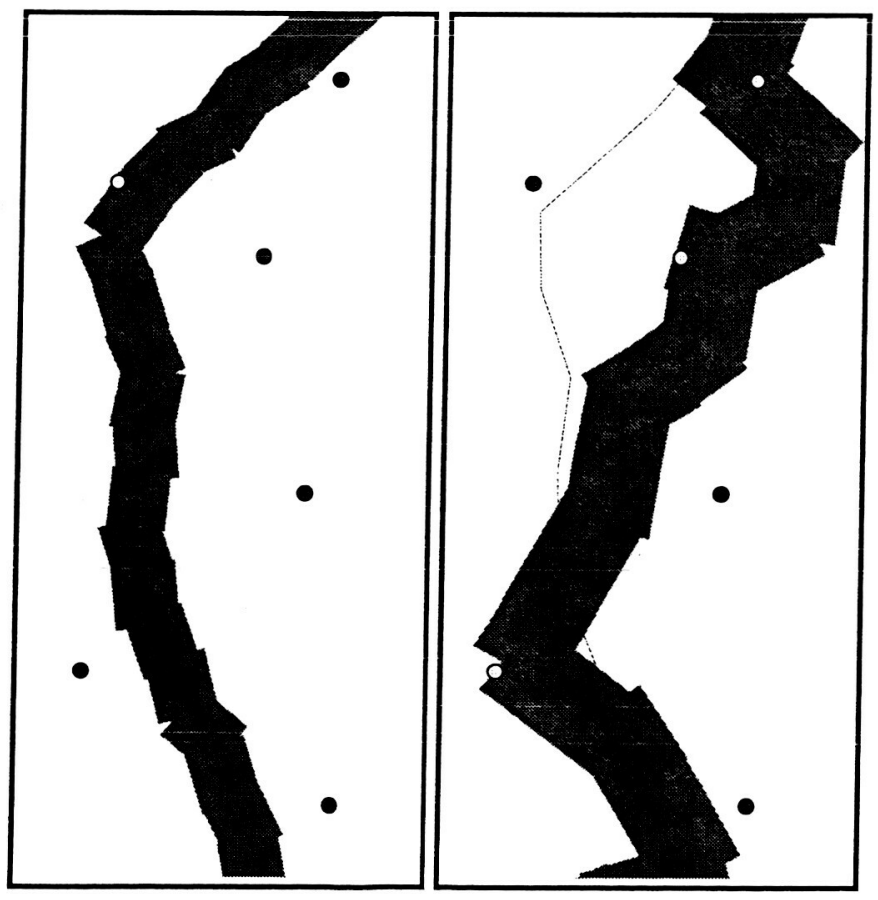

Figure 9. Imaging Performed by Terrain Following (Left) and CEL Autopilot (Right)

Dashed-Line Indicates Location of Riverbed. Red Circles: Unidentified Targets. Yellow Circle: Imaged Targets. 
Our final application was to examine better ways of managing search behaviors in flight for the adaptive selection of the best behavior. An emotional flight control system (EFCS) was created using the CEL architecture ${ }^{9}$. This autopilot manages internal states as a dynamic system that responds to continuous and discrete inputs from the sensors, closing the loop on both the laser altimeter (indirect sensor, continuous) and the camera's visual identification software (direct sensors, discrete). Using this additional sensor information in the autopilot, the EFCS would rely on a combination of the previous behaviors, selecting the behavior that seemed most appropriate given the discrete feedback received from the camera sensors. As hoped, the resulting system outperformed the less-intelligent terrain following autopilot as shown in Figure 9, although the results exhibited a larger standard deviation than the experiments performed with the previous autopilots.

It is anticipated the CEL architecture will find broad application to a number of robotics and UAV problems, as well as extensible to other flight behaviors and heuristic rules for discovery of terrain features of interest. It is also anticipated that the CEL architecture and bio-inspired autonomy in general, is well-suited to the two general aerial explorer mission categories addressed in this paper, though the work to date has focused on the surface imaging and interaction mission category. Much more work is required and, hopefully, will be carried out in the future.

\section{CONCLUDING REMARKS}

It is a powerful vision that one day aerial vehicles will fly through the skies of other planetary bodies in our Solar system. However, having made that somewhat bold prediction, it is essential that the scientific return on investment of such planetary aerial vehicle missions is maximized. This, in part, dictates that optimal solutions both from an instrument (i.e., cameras and/or other remote-sensor "imaging) as well as an autonomy perspective be developed and demonstrated. This in turn will require that a new approach to mission simulation for aerial explorers will be necessary. This paper has outlined the initial requirements for aerial explorers conducting aerial surveys; further, it has provided sample results from preliminary simulation work related to such aerial explorer survey missions. The results to date are quite promising and steps towards future work are outlined.

\section{ACKNOWLEDGMENTS}

The programmatic support of Drs. Butler Hine and Michael Shafto of the Computational Sciences Division was instrumental in making this work possible. Additionally, the technical input from Dr. Geoffrey Briggs, Science Director of the Center for Mars Exploration, is greatly appreciated. Finally, we bid a fond "fair winds and following seas" to Mr. Edwin Aiken for his unwavering support of aeronautics, rotorcraft, and planetary aerial explorers.

\section{REFERENCES}

1. Aiken, E.W., Ormiston, R.A., and Young, L.A., "Future Directions in Rotorcraft Technology at Ames Research Center," $56^{\text {th }}$ Annual Forum of the American Helicopter Society, International, Virginia Beach, VA, May 2-4, 2000.

2. Plice, L., Pisanich, G., Lau, B., and Young, L.A., "Biologically Inspired 'Behavioral' Strategies for Autonomous Aerial explorers on Mars," IEEE Aerospace Conference, Big Sky, MT, March 2003.

3. Young, L.A. and Pisanich, G., "Aerial Explorers and Robotic Ecologies," Second International Conference on Computing, Communication and Control Technologies (CCCT), Austin, TX, August 14-17, 2004.

4. Pisanich, G. and Young, L.A., “An Aerobot Ecology," Robosphere 2002: Workshop on Self-Sustaining Robot Ecologies, NASA Ames Research Center, Moffett Field, CA, November 2002. 
5. Young, L.A., Aiken, E.W., and Briggs, G.A., "Smart Rotorcraft Field Assistants for Terrestrial and Planetary Science," 2004 IEEE Aerospace Conference, Big Sky, MT, March 2004.

6. Pisanich, G., Young, L.A., Ippolito, C., Plice. L., Lau, B., and Lee, P., "Initial Efforts towards MissionRepresentative Imaging Surveys from Aerial explorers," SPIE (International Society of Optical Engineers) Electronic Imaging Conference, San Jose, CA, January 2004.

7. Pisanich, G., Ippolito, C., Plice, L, Young, L., and Lau, B., "Actions, Observations, and Decision-Making: Biologically Inspired Strategies for Autonomous Aerial Vehicles," AIAA Aerospace Sciences Meeting, Reno, NV, January 2004.

8. Young, L.A., Pisanich, G., and Ippolito, C., "Aerial Explorers," AIAA Aerospace Sciences Meeting, Reno, NV, January 2005.

9. Ippolito, C., Pisanich, G., and Young, L.A., "Cognitive Emotion Layer Architecture for Intelligent UAV Planning, Behavior and Control," 2005 IEEE Aerospace Conference, Big Sky, MT, March 2005.

10. Young, L.A. and Aiken, E.W., "Exploration: Past and Future Contributions of the Rotorcraft Division," AIAA $1^{\text {st }}$ Space Exploration Conference, Orlando, FL, January 2005.

11. Young, L.A., et al, "Design Opportunities and Challenges in the Development of Vertical Lift Planetary Aerial Vehicles," American Helicopter Society (AHS) Vertical Lift Aircraft Design Conference, San Francisco, CA, January 2000.

12. Maise, G., Powell, J., and Paniagua, J., "A Nuclear Ramjet Flyer for Exploration of Jovian Atmosphere," Forum on Innovative Approaches to Outer Planetary Exploration 2001-2020, Lunar and Planetary Institute (LPI) Report \# 1084, Houston, TX, February 21-22, 2001.

13. Lodders, K. and Fegley, Jr., B., The Planetary Scientist's Companion, Oxford University Press, 1998.

14. Yelle, R.V., Griffith, C.A., and Young, L.A., "Structure of the Jovian Stratosphere at the Galileo Probe Entry Site," Icarus 152, Academic Press, 331-346 (2001).

15. Showman, A.P. and Dowling, T.E., "Nonlinear Simulations of Jupiter's 5-Micron Hot Spots," Science, Vol. 289, September 8, 2000.

16. Young, Leslie A., et al, "Gravity Waves in Jupiter's Thermosphere," Science, Vol. 276, April 4, 1997.

17. Hueso, R., Sanchez-Lavega, A., and Guillot, T., "A Model for Large-Scale Convective Storms in Jupiter," (2002) Journal of Geophysical Research: Planets, 10.

18. Holland, G.J., et al, "The Aerosonde robotic aircraft: A new paradigm for environmental observations," Submitted to: Bulletin of the American Meteorological Society, June 30, 2000.

19. Holland, G.J., T. McGeer and H. Youngren, 1992: Autonomous Aerosondes for economical atmospheric soundings anywhere on the globe. Bull. Amer. Met. Soc., 73, 1987-1998.

20. McGeer, T. and Vagners, J., "Wide-Scale Use of Long-Range Miniature Aerosondes Over the World's Oceans," 2000.

21. Anon., "Autonomous Dynamic Soaring Platform for Distributed Mobile Sensor Arrays," DOE Report \# DE2002801001, June 2002. 
22. Bhatta, P. and Leonard, N.E., "Stabilization and Coordination of Underwater Gliders," $41^{\text {st }}$ IEEE Conference on Decision and Control, 2002.

23. Graver, J.G., et al, "Underwater Glider Model Parameter Identification," Proceedings of the $13^{\text {th }}$ International Symposium on Unmanned Untethered Submersible Technology, August 2003.

24. Cadogan, D., Smith, T., Lee, R., Scarborough, S., and Graziosi, D., "Inflatable and Rigidizable Wing Components for Unmanned Aerial Vehicles," 44 ${ }^{\text {th }}$ AIAA Structures, Dynamics, and Materials Conference, AIAA-2003-1801, Norfolk, VA, April 2003.

25. Hoerner, S.F., Fluid-Dynamic Lift, Self-Published by Author, 1965.

26. Greeley, R. et al, "Mars Scientific Goals, Objectives, Investigations, and Priorities (2001 version)," http://mepag.jpl.nasa.gov/reports/

27. Avery, S. et al, "Review of NASA's Earth Science Enterprise Research Strategy for 2000-2010", Space Studies Board, National Research Council, http://www7.nationalacademies.org/ssb/SSB ESE review 2000 2010.pdf

28. Anon, "New Frontiers in the Solar System, An Integrated Exploration Strategy", Space Studies Board, National Research Council, http://www.aas.org/ dps/decadal/

29. Lee, M., Weidner, R. J., "In-Situ Site Knowledge System: Mars Technology Program", 2002 IEEE Aerospace Conference, Big Sky, MT, March 2005. 